\title{
Chapter 3 \\ Addressing the Learning Crisis: Basic Skills and 21st Century Skills
}

\author{
Moses Oketch
}

Abbreviations

COVID-19 coronavirus disease

LLMICs low- and lower-middle-income countries

OECD Organisation for Economic Co-operation and Development

PISA Programme for International Student Assessment

RCT randomized controlled trial

RISE Research on Improving Systems of Education

\subsection{Introduction}

Student performance needs to be improved substantially, particularly in low- and lower-middle-income countries (LLMICs), ${ }^{1}$ which have seen gains in enrollment in recent years, in order to achieve basic skill requirements. There is also ample evidence that shows that improving student performance may have a high economic and social payoff (Carnoy et al. 2015).

\footnotetext{
${ }^{1}$ For fiscal year (FY) 2021, low-income economies are defined as those with a gross national income (GNI) per capita, calculated using the World Bank Atlas method, of $\$ 1,035$ or less in 2019; lower-middle-income economies are those with a GNI per capita between $\$ 1,036$ and $\$ 4,045$. Source World Bank. World Bank Country and Lending Groups. https://datahelpdesk.worldbank.org/kno wledgebase/articles/906519-world-bank-country-and-lending-groups.
}

\footnotetext{
M. Oketch ( $\varangle)$

Centre for Education and International Development, Institute of Education, University College

London, London, UK

e-mail: m.oketch@ucl.ac.uk
}

Foreign, Commonwealth and Development Office, London, UK

(C) The Author(s) 2021

S. Ra et al. (eds.), Powering a Learning Society During an Age of Disruption,

Education in the Asia-Pacific Region: Issues, Concerns and Prospects 58,

https://doi.org/10.1007/978-981-16-0983-1_3 
There is a growing body of empirical data and evidence that can begin to help policy analysts and policy makers in LLMICs decide which strategies are most likely to raise learning achievement and ensure that education systems can meet the demand for the skills needed today. Even in the more economically advanced countries, where evidence shows that learning levels are typically very low by standards of the Organisation for Economic Co-operation and Development (OECD), data is now available that makes the scale of the global learning crisis much easier to understand in a wide range of contexts. Learning rather than schooling has now become front and center and is an issue for both developed and developing countries. Estimates by $\operatorname{OECD}(2015$, p. 38) show that more that $70 \%$ of students do not acquire basic skills by age 14-15 years in Ghana, Honduras, and South Africa. In this category of countries, the best performing country is Slovak Republic where less than $30 \%$ are categorized as not acquiring these skills by ages 14-15. In the more economically advanced countries, many countries, including Ukraine, United Kingdom, and the United States have more than $20 \%$ of their students not acquiring basic skills by ages 14-15. The best performing countries in this category are Estonia; Hong Kong, China; and the Republic of Korea, where students who have not acquired basic skills by ages $14-15$ comprise less than $10 \%$ (Fig. 3.1).

\subsection{Defining Basic Skills}

Rossiter et al. (2018) argue that there is no single definition of basic skills, while international reports refer to "basic skills like literacy and numeracy" (World Bank 2018). Others have shown that failure to learn to read is associated with falling behind or dropping out of school altogether (Abadzi 2006). Others refer to "transferable skills" in addition to or in combination with literacy and numeracy (DFID 2018). In economics terms, basic skills refer to ability to compete in the economy of the future, wherein workers need strong basic skills and foundations for adaptability, creativity, and lifelong learning (World Bank 2018, xii), including adaptability, creativity, and lifelong learning. Rossiter et al. (2018, p. 14) argue that "another approach to defining basic skills emphasizes the social foundations to participate fully in society (a right, by virtue of being a member)"-which is a broader definition of basic skills. Educational assessment, as used for example, in the acquisition of at least Level 1 skills in the OECD Programme for International Student Assessment (PISA; see examples in Box 3.1), is another commonly used reference to basic skills (Rossiter et al. 2018, p. 14). 
3 Addressing the Learning Crisis ...

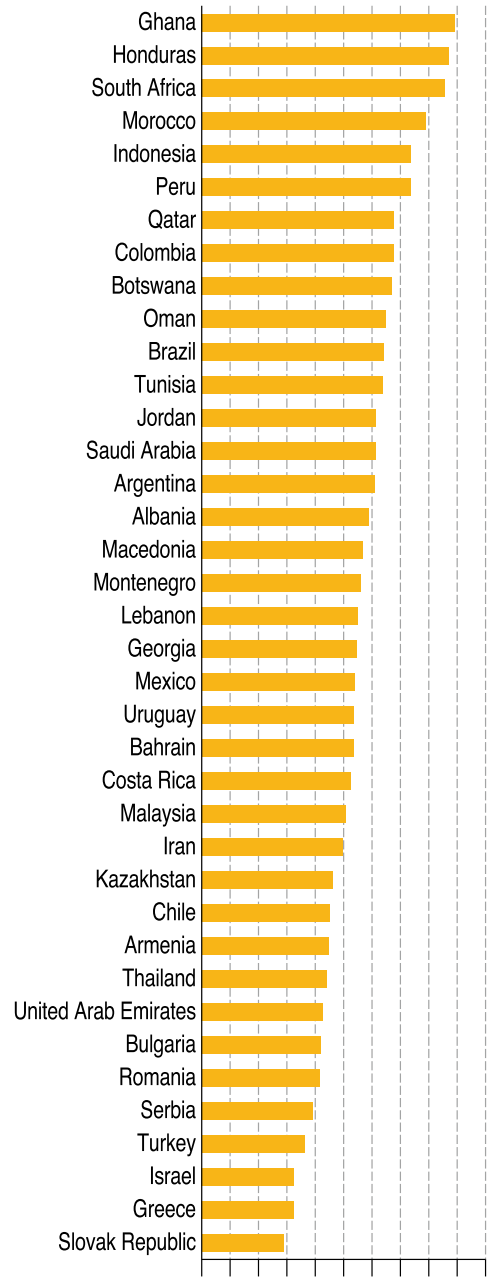

0102030405060708090100

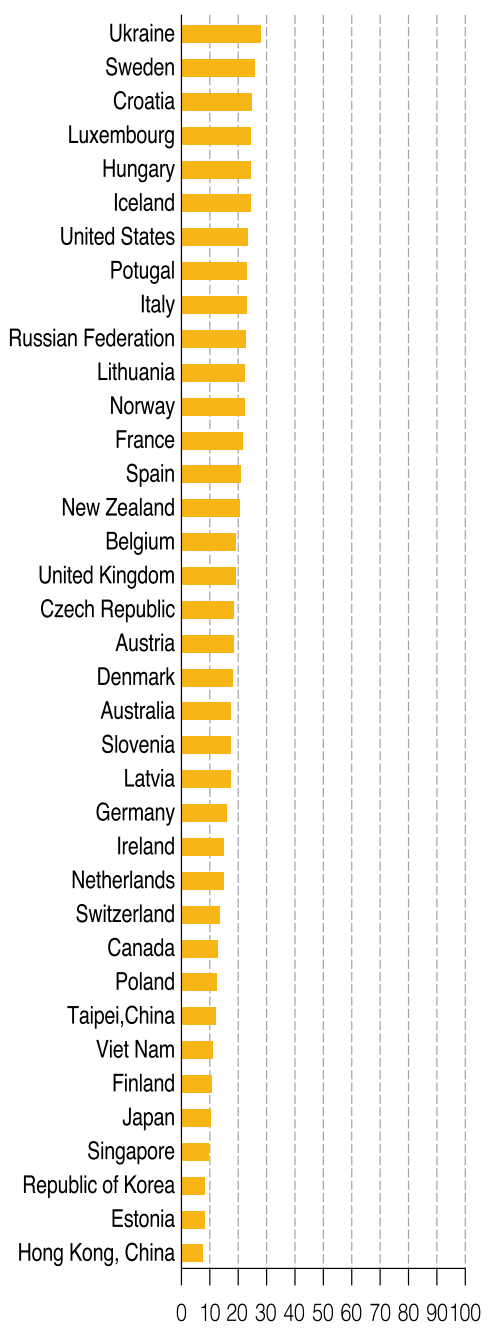

Fig. 3.1 Estimates of students not acquiring basic skills by age 14-15 (\%) (Student performance particularly in low- and lower-middle-income countries needs to be improved substantially, to achieve basic skill requirements). Source Organisation for Economic Co-operation and Development. 2015. Universal basic skills: What countries stand to gain. Paris: OECD Publishing 


\section{Box 3.1 PISA Proficiency Scale Description for Mathematics and Reading}

\begin{tabular}{l|l}
\hline PISA mathematics level 1 & PISA reading level 1 \\
\hline $\begin{array}{l}\text { At Level 1, students can answer questions } \\
\text { involving familiar contexts where all } \\
\text { relevant information is present and the }\end{array}$ & $\begin{array}{l}\text { Tasks at this level require the reader to } \\
\text { locate one or more independent pieces of } \\
\text { explicitly stated information; to recognise }\end{array}$ \\
$\begin{array}{l}\text { questions are clearly defined. They are able } \\
\text { to identify information and to carry out } \\
\text { routine procedures according to instructions }\end{array}$ & $\begin{array}{l}\text { text about a familiar topic, or to make a } \\
\text { simple connection between information in } \\
\text { in explicit situations. They can perform } \\
\text { actions that are almost always obvious and } \\
\text { follow immediately from the given stimuli. }\end{array}$ \\
$\begin{array}{l}\text { Typically the required information in the } \\
\text { text is prominent and there is little, if any, } \\
\text { competing information. The reader is } \\
\text { explicitly directed to consider relevant } \\
\text { factors in the task and in the text. }\end{array}$ \\
\hline
\end{tabular}

PISA = Programme for International Student Assessment

Note PISA Reading Level 1 is split into Level 1a (slightly higher) and Level 1b (slightly lower). This box shows the statement for Level 1a

Source Rossiter, J. et al. 2018. Delivering on every child's right to basic skills: Summative report. Oxford: Young Lives

Using one or more of the above definitions of basic skills has led researchers such as Rossiter et al. (2018) to conclude that the majority of children in LLMICs are off-track in learning to master these basic skills. The severity of this problem is illuminated by the UIS (2017) presentation on global distribution of primary school-age population who are not achieving the minimum proficiency in reading, where sub-Saharan Africa is the worst performing region with about $87 \%$ not achieving proficiency. This is followed closely by Central and South Asia where approximately $81 \%$ are not achieving proficiency in reading (Fig. 3.2).

Furthermore, there is a strong association between basic skills and economic growth rates across countries as illustrated by Hanushek and Woessmann (2015) in Fig. 3.3.

Majority of children in low-income countries attend school. ${ }^{2}$ Nearly $90 \%$ of primary-school-aged children globally are enrolled in school, and in LLMICs, as a whole, far more than half complete primary school (Crouch 2020, p. 1). However, access is still unequal and school quality is generally low on the measures available. There is great variation in learning outcomes among countries at similar levels of income: in some cases, there are lower levels of student achievement in countries with greater expenditure in education and higher level of income, compared to countries with lower income and lower education expenditure. For example, the 2015 PISA results show exceptional performance for Viet Nam, a lower-middle-income country

\footnotetext{
${ }^{2}$ See UNESCO Institute for Statistics. http://data.uis.unesco.org/.
} 
3 Addressing the Learning Crisis ...

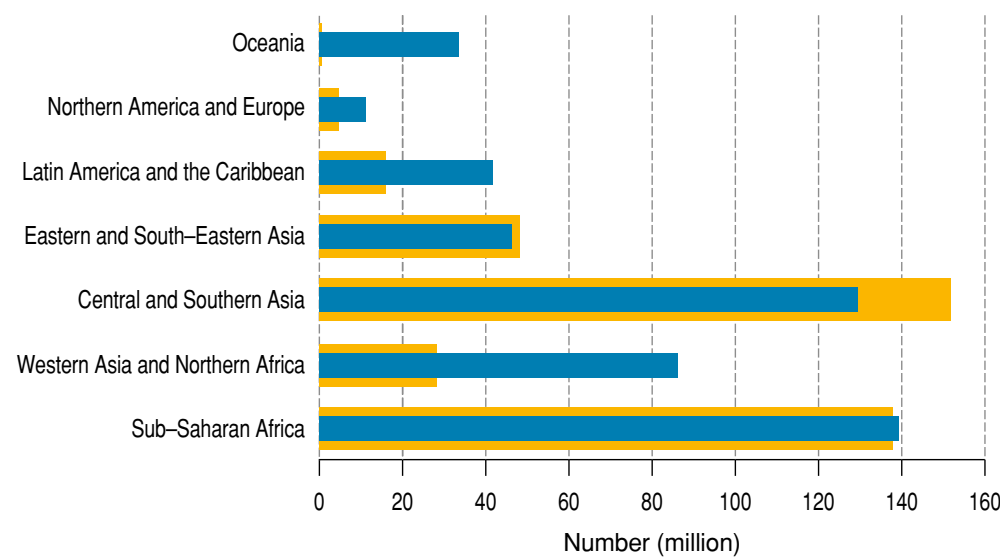

Numbers (bottom axis) Proportion in region (top axis)

Fig. 3.2 Global distribution of primary school-age population not achieving minimum proficiency levels in reading (Reading, which is one of the basic skills, is severely lacking in majority of children in low- and lower-middle-income countries). Source UIS. 2017. Delivering on every child's right to basic skills: Summative report. Eds. J. Rossiter, M. Woodhead, C. Rolleston, and R. Moore, 15. Oxford: Young Lives

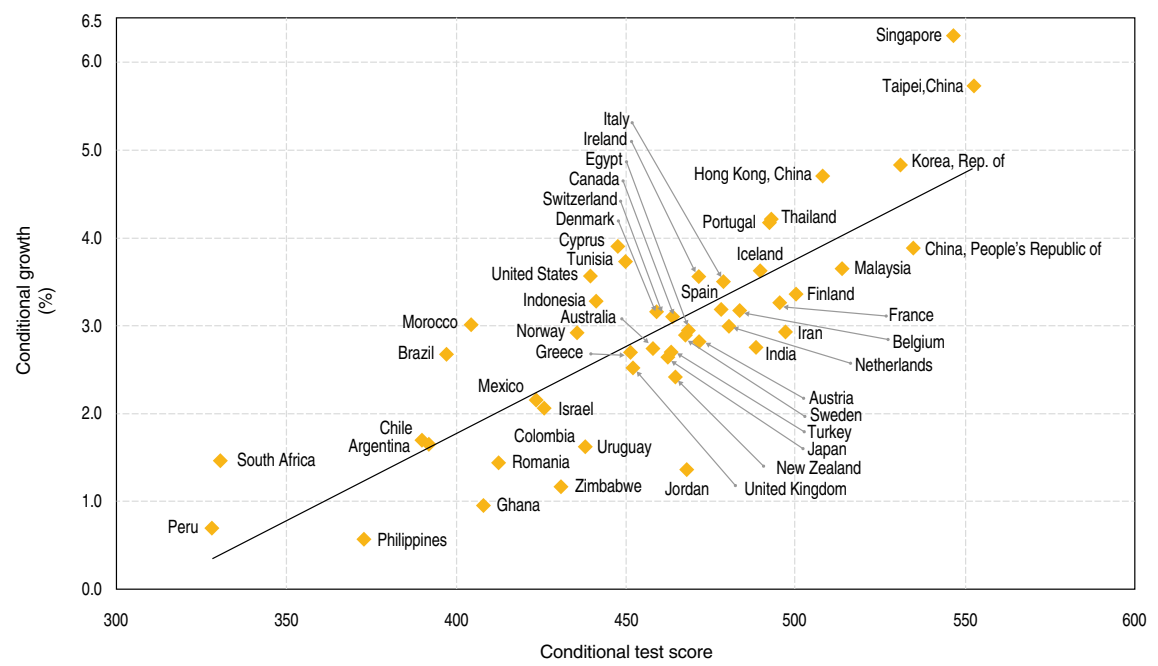

Fig. 3.3 Collective skills and economic growth rates across economies (There is a strong association between basic skills and economic growth). Source Hanushek, E.A., and L. Woessmann. 2015. Universal basic skills: What countries stand to gain. Paris: OECD Publishing. https://doi. org/10.1787/9789264234833-en 
Universal scale score (maximum, median, minimum) In PISA 2,000 units

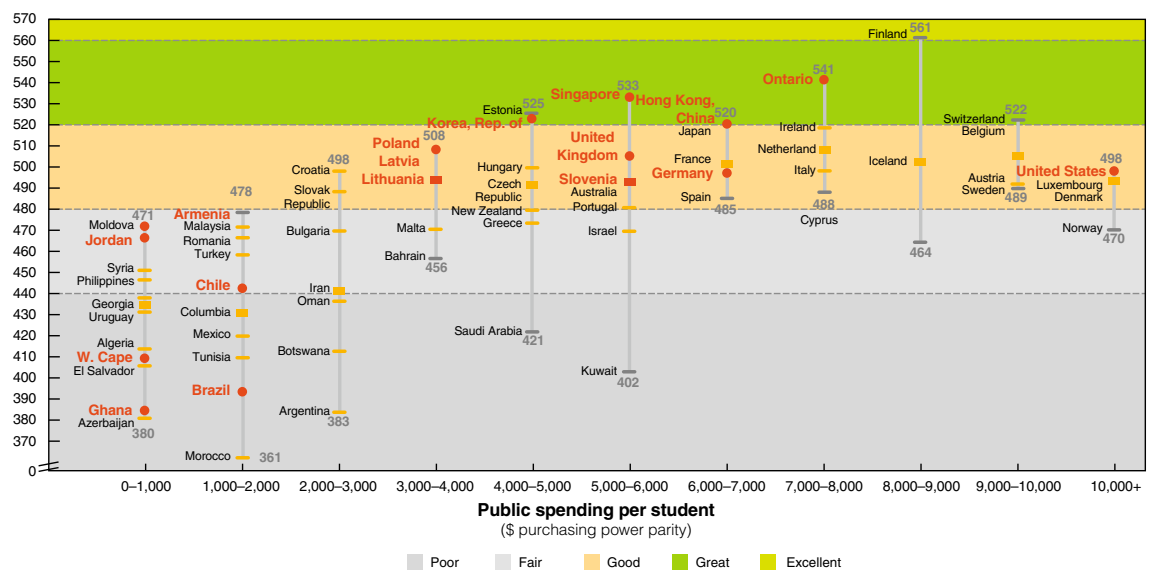

Fig. 3.4 Public spending per student (Not all education systems are equal. In some cases, there are lower levels of student achievement in countries with greater expenditure in education and higher level of income [see Peru in the figure], compared to countries with lower income and lower education expenditure [see Viet Nam]). Source McKinsey\&Company. 2010. Exhibit 3: Systems with similar spend have widely ranging levels of performance

with a history of recent conflict, whereas the results for Peru, a considerably wealthier country, are near the bottom of the ranking (Fig. 3.4). In the Southern and East Africa Consortium for Monitoring Educational Quality countries, Kenya, which is a lower-middle-income country, outperforms both Botswana and South Africa, which are middle-income countries that spend a lot more on education than Kenya. Such evidence suggests that increasing per pupil expenditure alone is not the solution to the learning crisis. Student learning is a complex process and is subject to factors within and outside school, and some of these factors are outside the control of the school authorities (Carnoy et al. 2015).

Evidence from a large body of literature across many countries is robust on the impact of children's backgrounds and teacher quality on learning. Among these is the Research on Improving Systems of Education (RISE) Programme, a global research endeavor that seeks to understand how education systems in developing countries can overcome the learning crisis. ${ }^{3}$ RISE is helping increase attention on the importance of macro drivers of system performance that contribute to student learning. Large differences between systems demand much greater attention to the macro level, and to the interrelationships between macro-level systemic factors and the micro and meso levels of pupil, class, teacher, and school (Oketch et al. 2020).

While it is obvious in one sense that the quality of an education system cannot exceed the quality of its teachers, teachers with similar characteristics in one setting may "produce" outcomes quite different from those in another, as has been shown in several studies of private versus public schooling. Further, macro-level factors

\footnotetext{
${ }^{3}$ See Research on Improving Systems of Education Programme. https://riseprogramme.org/.
} 
School A

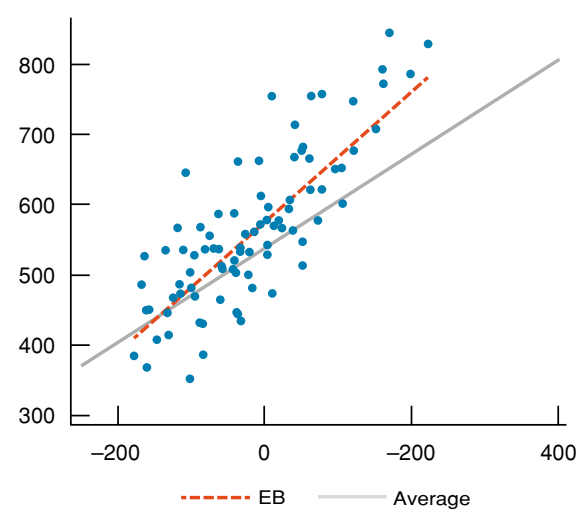

Beginning of the year test score (centered on zero) $(X)$ End of the year test score $(Y)$
School B

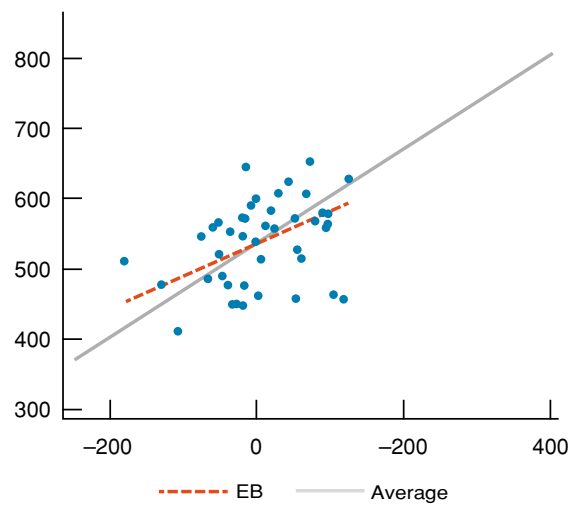

Beginning of the year test score (centered on zero) End of the year test score $(Y)$

Fig. 3.5 Learning gains in two schools-beginning and end-of-year test scores (This figure is an illustration of two schools purposively selected for having different groups of pupils and different patterns of learning progress. It suggests that research focused on the dynamics of systemic change at all levels — national, regional, classroom - is required to establish potentially successful reform pathways, and to understand the blockages that make learning more relevant for the development of basic skills). Note Based on Ethiopia School Survey data. Source Oketch, M., C. Rolleston, and J. Rossiter. 2020. Teacher value-added using Young Lives Ethiopia school survey data-Diagnosing the learning crisis: potential applications of value-added analysis. RISE Insight Series. No. 2020/016. https://doi.org/10.35489/BSG-RISE-RI_2020/014

frequently resist reduction to simple proxy indicators. Measures such as per-pupil spending, teacher-pupil ratios, etc., explain relatively little of the differences between systems. Historical and political factors may explain somewhat more (Carnoy et al. 2015), but these are less well understood and less readily quantified. Moreover, as can be seen in Fig. 3.5, diagnoses of systemic failure are not solutions in themselves, as illustrated in a comparison of two schools in Ethiopia's context (see Oketch et al. 2020, p. 3).

According to Oketch et al. (2020), some schools can show substantial progress for students with above average prior achievement, and limited progress for students with below average prior achievement. Other schools can show a more homogenous group of students (in terms of prior achievement), with more progress among those with below average prior achievement-perhaps at the cost of high early achievers' progress. In this context, schools with substantial progress for students with above average prior achievement would be considered to show a greater than average value-added (effectiveness) than schools with more progress among those with below average prior achievement. However, considered more carefully, both categories of schools generate effectiveness by improving learning among different groups of pupils - one category of schools raises the bar for the brightest pupils, while another category of schools adds value more evenly across the range of prior learning levels (Oketch et al. 2020, p. 3). Diagnoses of systemic failure may not be able to reveal this 
heterogenous classroom context that are common in low- and lower-middle-income countries.

Furthermore, this situation illustrated in Oketch et al. (2020) suggests that research focused on the dynamics of systemic change at all levels-national, regional, classroom-is required to establish potentially successful reform pathways and to understand the blockages that make learning more relevant for the development of basic skills. The search for uniformities, sometimes evident in international comparisons such as those in the education monitoring reports of the United Nations Educational, Scientific and Cultural Organization (UNESCO), may not be the approach to this kind of research. Nevertheless, understanding the structural changes that accompany successful reforms and describing them comprehensively should be considered an important step in addressing system performance and learning, and infusing new notions of how to significantly raise student achievement. Methodologically, Big Data can be pulled into the education sector to inform granular, real-time data and insights, which in turn inform differentiated policies and actions.

\subsection{System Diagnostics}

Comparative education systems analysis is required to provide better evidence on both the efficiency and effectiveness of education systems. RISE explains that examining an education system holistically_or systems thinking-allows one to see what components are not working together to produce learning. ${ }^{4}$ This forms the starting point for establishing summary performance indicators at the system level for learning outcomes that can serve basic skills requirements. Differences in performance depend both on differences in inputs and outcomes, while the key to improving performance within a limited resource envelope is in improving the efficiency and effectiveness with which inputs are employed.

The development of system metrics is an important part of this area of research. For example, simple measures such as cost-effectiveness indicators (e.g., dollars per increment in pupil test scores) are rarely available, but these are what can greatly help to compare countries that spend over $\$ 10,000$ per student with those that spend $\$ 1,000$ or less, as seen from the PISA test based on the computation by Mourshed et al. (2010). A more effective analysis of learning outcomes can be the contribution that each teacher makes to improving learning based on the composition of the class that they teach, as illustrated in Oketch et al. (2020).

However, measures of performance, efficiency, and effectiveness do not provide explanations for how and why an education system is where it is or what works to improve learning outcomes or address the learning crisis. The development of system diagnostic tools is key for understanding the reasons for differences in (summary) system performance. These tools set out to identify strengths and weaknesses in

\footnotetext{
${ }^{4}$ See Research on Improving Systems of Education. Systems thinking. https://riseprogramme.org/ systems-thinking.
} 
systems. Weak links in education systems are especially important owing to the interdependence of components within a system. As pointed out by Crouch (2020, pp. 1-2), "One reason education systems struggle to address the learning crisis is that the quality of the sub-systems (curricular design and lesson plans, textbook design, assessment tools, and teacher coaching and support) is often low, and in some cases missing altogether. Just as importantly, though, the coherence among these 'core' sub-systems is often missing."

Still, while system diagnostics provide a fuller understanding of the sources of good or poor performance at the present, they do not provide a way forward with respect to specific reforms needed (or likely to be effective). For example, if poor school accountability is identified as a weak link that explains high levels of teacher absenteeism (a potential cause of low learning progress in LLMICs), the question of how to improve teacher attendance remains open.

Pilot studies using randomized controlled trials (RCTs) offer some insight at a small scale on potential mechanisms of change, but if the "blockage" lies at the macro level or system level, for example in terms of industrial relations with teachers' unions, there is a danger of oversimplification or reduction when using experimental evidence. This is the well-known problem of external validity of RCT designs. With respect to macro-level questions, such as reform of the curriculum, alternative solutions such as decentralizing curricular decisions or centralizing them could equally improve or worsen system performance, depending on the institutional and political-economic context. A fundamental question then is how do successful systems manage to be successful, particularly when there are specific "country effects" that cannot be explained by differences in pupils' socioeconomic background and variables used to measure teacher quality or classroom conditions (Carnoy et al. 2015). According to Crouch (2020, p. 2), "In the context of these coherence and support challenges, there are several promising examples of how national and sub-national governments in low- and middle-income countries have aligned their sub-systems. These governments are either seeing rapid improvements in learning outcomes or are sustaining learning levels that are better than their peers."

Crouch (2020, p. 1) proposes the following as tips considered to lead to system improvement:

(i) Focus on just a very few achievable indicators, and place foundational learning at the forefront for a country emphasizing learning.

(ii) Use data to drive both initial "wake-up" and stock taking, but also to help the teaching process along.

(iii) Emphasize teaching by teachers who are already in place.

(iv) Provide strong motivation through support that works.

(v) Use tight management so there is some degree of centralism and prescriptiveness as to pedagogy and other inputs, but after having iterated and adapted to context. 


\subsection{Addressing the Learning Crisis}

\subsubsection{Reform Pathways}

The effectiveness of education reforms to address a learning crisis and align with basic skills with respect to individual dimensions of the education system, such as curricula or teacher training, is limited to a large extent by the next weakest link in the system. For example, improving textbooks may yield improvements in learning, but these improvements will depend upon teachers' knowledge and training being adequate to employ the new books effectively and on regular assessment of pupils' learning feeding back into teaching and learning. Many of these links are processes rather than more readily measurable inputs (Carnoy et al. 2015).

Reform pathways are more than mechanisms for change of individual features of a system (e.g., high teacher absenteeism as above) but also reflect the chain of linkages required for sustainable system reform. Reform pathways describe routes from the present status quo to improved system performance, based on a holistic approach that results from thorough diagnosis of weaknesses and strengths plus a full understanding of the interdependence between mechanisms of change. This is related to what the RISE research is attempting to accomplish by seeing system coherence as analogous to that of a car with a motor, transmission, axles, and wheels; and that "the pieces have to all work together as sometimes fixing one piece at a time won't make any difference" (Pritchett 2018, p. 1). In turn, this requires an understanding of the why questions that relate to the status quo-what are the reasons why the reforms that may be considered necessary for learning quality for basic skills have not been undertaken or have not succeeded? How are education standards that produce higher achievement developed?

\subsubsection{Blockages and Catalysts for Reform to Address the Learning Crisis}

The question to ask here includes under what circumstances are effective reforms for improving learning undertaken? What stands in the way of effective reforms?

These questions relate largely to the political economy of education systems, an area that is gaining better recognition today than it did before. This is an area where research is required at the national level to understand decision-making processes and their influences, while synthesis across countries to provide a framework for understanding political economies of education is also an important area of research work. Here, again, the RISE Programme offers some insights in a blog written by Lant Pritchett: "A key part of the RISE agenda is to focus on getting to systems of basic education that are coherent around learning" (Pritchett 2018, p. 1). The RISE Programme is divided into three parts: (i) a symptomatic description of existing conditions-what is known about the current levels and recent progress 
in enrollments, learning, and the standard descriptions of available inputs (e.g., class sizes, teacher labor force, etc.); (ii) analytic diagnostic of key elements of the education system; and (iii) what are the system changes required, their impact and why (or why not) those changes are likely to produce impacts. This ultimately leads to policy influence.

\subsection{Policy Influence}

Providing evidence for informed policy change in education requires not only technical analyses of performance, diagnostic tools for understanding reasons for low performance, and identification of mechanisms of change. It also requires an understanding of the political economy of such change so as to link mechanisms to the systems in which they are most likely to be effective. Any evidence that is brought up, and how this evidence is utilized, are important to understand why some education systems are simply better than others in producing learning gains both inside and outside of school. Consolidating research from different kinds of studies can help with evidence that leads to figuring out how to bring together vertical strands of work that the international community is doing in education. For example, the early grade reading work led by Piper et al. (2014) in East Africa, which is similar to the vertical work in health on malaria, HIV/AIDS, etc., are being "horizontalized" or integrated by health authorities so that these successful programs can inform standard practice. This also helps to link evidence on specific subjects over the past few years into systems work related to improving learning outcomes that are relevant for basic skills (see also Crouch 2020).

These arguments suggest that in order to address the learning crisis, it may be necessary to consider a wide range of options including the following:

(i) more rigorous examination of natural variation in systems than has been done up to now;

(ii) use of more systematic, perhaps RCTs or other rigorous methods of evaluation of subsystems of countries, such as provinces or counties, as noted by Crouch (2020);

(iii) research on why effective systems use more of a systematic bureaucratic learning approach than a rigorous experimentation approach (because it is not clear that the best systems became that way by doing a lot of randomized or pilot studies); and

(iv) study on why effective systems also use a lot of measurement mixed with tatonnement processes and accountability, which gradually ratchet up performance and spread lessons learned in what one could call an evolutionary rather than designed manner (Crouch 2020).

This is not to deny the importance of knowledge derived from RCT studies and other similar pilot approaches. But it is to say that, when it comes to systems knowledge, rather than micro school practices and pedagogical norms, we need 
something beyond RCTs and the like, although as rigorous (Oketch 2019). This is similar to the description by Pritchett (2018, p. 1) on the RISE systems approach, in which he notes the focus of RISE on the coherence of accountability systems (similar to the notion of the alignment of actors).

OECD (2015) suggests that economic growth of a country is somewhat strongly dependent on investment in education, a classic human capital theory argument. The idea is that improving the population's collective skills level is necessary for a country's path to economic growth (Hanushek and Woessmann 2015). Collective is the key phrase here, such that systems that only produce basic skills for a few children cannot be thought of as developing these collective skills. This is the learning crisis scenario in most LLMICs that have witnessed unprecedented growth in enrollment in recent decades, itself a great story. The question is how to achieve this collective skills level fast, in systems that are already far behind and experiencing a learning crisis. Crouch and Gustafsson (2018) find that the fastest way of increasing these collective skills is to move up from the bottom, analogous to illustration of schools in Oketch et al. (2020, p. 3), which add value more evenly across the range of prior learning levels. This is prioritizing the lowest performers as the fastest path to higher average skills (Crouch and Gustafsson 2018). OECD (2015) notes that replicating best performance in as many countries is the likely pathway to achieving the basic skills by 2030. The ultimate question however, is how can this replication be done successfully in many varied contexts?

\subsection{Conclusions}

The world is struggling with interconnected crises that amplify and will most likely extend existing learning crises in education in LLMICs. Such is the scenario in the wake of the COVID-19, which will have significant impacts on achievements in basic skills. Drastic measures will be required to build back better from a crisis within a crisis situation in education; otherwise, there will be a significant human capital loss in the next generation. Building back better or building back equitably and powering learning societies in the age of disruption will require doubling of efforts to increase attention on the importance of macro level drivers of system performance that contribute to student learning. Building back better makes this call for coherent systems accountability approach even more urgent.

\section{References}

Abadzi, H. 2006. Efficient learning for the poor: Insights from the frontier of cognitive neuroscience. Washington, DC: World Bank. https://openknowledge.worldbank.org/handle/ 10986/7023. License: CC BY 3.0 IGO. 
Carnoy, M., M. Ngware, and M. Oketch. 2015. The role of classroom resources and national education context in student learning gains: Comparing Botswana, Kenya, and South Africa. Comparative Education Review 59 (2): 199-233.

Crouch, L. 2020. Systems implications for core instructional support lessons from Sobral (Brazil), Puebla (Mexico), and Kenya. RISE Insight Series. No. 2020/020. https://doi.org/10.35489/bsgrise-ri_2020/020.

Crouch, L., and M. Gustafsson. 2018. Worldwide inequality and poverty in cognitive results: Cross sectional evidence and time-based trends. RISE Working Paper. No. 18/019. Oxford: RISE.

Department for International Development (DFID). 2018. DFID education policy 2018: Get children learning. London.

Hanushek, E.A., and L. Woessmann. 2015. Universal basic skills: What countries stand to gain. Paris: OECD Publishing. https://doi.org/10.1787/9789264234833-en.

Mourshed, M., C. Chijioke, and M. Barber. 2010. How the world's most improved school systems keep getting better. London: McKinsey and Company.

Oketch, M.O. 2019. Randomized control trials: Limitations for explaining and improving learning outcomes. In World yearbook of education 2019 comparative methodology in an era of big data and global networks, eds. R. Gorur, S. Sellar, and G. Steiner-Khamsi. Abingdon: Routledge.

Oketch, M., C. Rolleston, and J. Rossiter. 2020. Teacher value-added using Young Lives Ethiopia school survey data-Diagnosing the learning crisis: Potential applications of value-added analysis. RISE Insight Series. No. 2020/016. https://doi.org/10.35489/BSG-RISE-RI_2020/014.

Organisation for Economic Co-operation and Development (OECD). 2015. Universal basic skills: What countries stand to gain. Paris: OECD Publishing.

Piper, B., S.Z. Simmons, and A. Mugenda. 2014. Improving reading outcomes in Kenya: First-year effects of the PRIMR Initiative. International Journal of Educational Development 37: 11-21.

Pritchett, L. 2018. What we learned from our RISE baseline diagnostic exercise. https://riseprogr amme.org/blog/baseline_diagnostic_exercise_1. Accessed 2 November 2020.

Research on Improving Systems of Education (RISE) Programme. https://riseprogramme.org/.

RISE. Systems thinking. https://riseprogramme.org/systems-thinking.

Rossiter, J., et al. 2018. Delivering on every child's right to basic skills: Summative report. Oxford: Young Lives.

UNESCO Institute for Statistics (UIS). http://data.uis.unesco.org.

UIS. 2017. Delivering on every child's right to basic skills: Summative report. Eds. J. Rossiter, M. Woodhead, C. Rolleston, and R. Moore. Oxford: Young Lives.

World Bank. 2018. World development report (2018): Learning to realize education's promise. Washington, DC.

World Bank. World Bank country and lending groups. https://datahelpdesk.worldbank.org/knowle dgebase/articles/906519-world-bank-country-and-lending-groups. Accessed 2 November 2020. 
The opinions expressed in this chapter are those of the author(s) and do not necessarily reflect the views of the Asian Development Bank, its Board of Directors, or the countries they represent.

Open Access This chapter is licensed under the terms of the Creative Commons Attribution-NonCommercial 3.0 IGO license (http://creativecommons.org/licenses/by-nc/3.0/igo/) which permits any noncommercial use, sharing, adaptation, distribution and reproduction in any medium or format, as long as you give appropriate credit to the Asian Development Bank, provide a link to the Creative Commons license and indicate if changes were made.

Any dispute related to the use of the works of the Asian Development Bank that cannot be settled amicably shall be submitted to arbitration pursuant to the UNCITRAL rules. The use of the Asian Development Bank's name for any purpose other than for attribution, and the use of the Asian Development Bank's logo, shall be subject to a separate written license agreement between the Asian Development Bank and the user and is not authorized as part of this CC-IGO license. Note that the link provided above includes additional terms and conditions of the license.

The images or other third party material in this chapter are included in the chapter's Creative Commons license, unless indicated otherwise in a credit line to the material. If material is not included in the chapter's Creative Commons license and your intended use is not permitted by statutory regulation or exceeds the permitted use, you will need to obtain permission directly from the copyright holder.

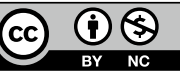

